\title{
ASMENŲ, SERGANČIŨ IŠSĖTINE SKLEROZE, PUSIAUSVYROS, GRIUVIMO RIZIKOS, NUOVARGIO BEI PAŽINTINIŲ FUNKCIJŲ KAITA, TAIKANT KOMPLEKSINĘ KINEZITERAPIJOS PROGRAMĄ
}

\author{
Martyna Rukaitė , Edita Jazepčikienė \\ ${ }^{1}$ Lietuvos sveikatos mokslu universiteto Medicinos akademijos Reabilitacijos klinika
}

Raktažodžiai: išsètinė sklerozè, kompleksinė kineziterapijos programa, pusiausvyra, griuvimo rizika, nuovargis, pažintinès funkcijos.

\section{Santrauka}

Tyrimo pagrindimas. Išsėtinè sklerozė (IS) pasireiškia daugialypiais simptomais, tokiais kaip nuovargis, pusiausvyros bei pažintinių funkcijų sutrikimai. Kasdienis nuovargis didina griuvimo riziką, mažina aktyvumą, motyvaciją. Atsižvelgiant ị ligos kompleksiškumą, siekta išsiaiškinti, ar kompleksinè kineziterapijos programa turi itakos pusiausvyros, griuvimo rizikos, nuovargio bei pažintinių funkcijų rodikliams IS sergantiems asmenims. Tikètina, kad minètų rodiklių kaita gali priklausyti nuo paros laiko, kuriuo atliekami pratimai. Tikslas - ivvertinti asmenų, sergančių IS, pusiausvyros, griuvimo rizikos, nuovargio bei pažintinių funkcijų kaitą, taikant kompleksinę kineziterapijos programą, priklausomai nuo procedūrų atlikimo laiko. Metodai. 20 tiriamujų, Kauno apskrities sergančiujų išsètine skleroze draugijos narių. Tiriamieji buvo suskirstyti ị dvi poveikio grupes. Tiriamiesiems buvo taikoma kompleksine kineziterapijos programa, kurią sudarè tempimo, liemens stabilizavimo bei sensomotoriką lavinantys pratimai ir dvigubos užduoties metodas. Kiekvienai tiriamujų grupei taikyta 10 kineziterapijos procedūrų, kas antrą dieną. Pirmajai grupei kineziterapija taikyta ryte, antrajai - po pietų. Tyrimo pradžioje ịvertinta pusiausvyra, griuvimo rizika, nuovargis bei pažintinès funkcijos. Baigus tyrimą, atliktas pakartotinis funkcijų vertinimas. Tyrimo rezultatai. Vertinant kompleksinès kineziterapijos programos efektyvumą priklausomai nuo procedūrų atlikimo laiko, pirmosios tiriamosios grupès dinaminès pusiausvyros, griuvimo rizikos, bendrojo bei protinio nuovargio, pažintinių funkcijų rodiklių pagėėjimas buvo reikšmingesnis, nei antrosios grupès $(p<0,05)$. Išvados. Dinaminès pusiausvyros rezultatai geresni toje grupejje, kurioje kompleksinè kineziterapijos programa taikyta ryte. Griuvimo rizikos sumažèjimas ryškesnis toje grupeje, kuri pratimų programą atliko ryte. Bendrasis ir protinis nuovargis sumažejo tik rytinejje grupejje. Tiriamujų pažintinès funkcijos pagerèjo toje grupèje, kuriai kineziterapijos programa vykdyta ryte.

\section{Ivadas}

Išsètinè sklerozė (IS) yra lètinè autoimuninè centrinès nervų sistemos (CNS) liga, kuria sergant pasireiškia uždegiminiai, demielinizacijos procesai bei aksonų pažaida net ir ankstyvose ligos stadijose. Liga daugiausiai paveikia 2040 metų asmenis. Dažniau serga moterys [1]. Asmenims, sergantiems IS, gali pasireikšti fizinè negalia, nuovargis, skausmas, šlapinimosi bei tuštinimosi problemos, kognityvinių funkcijų sutrikimai, sergantieji gali turèti psichologinių ir elgesio problemų. Šių sutrikimų poveikis daugialypis, pakinta asmens veikla (funkcija) ir dalyvumas, todèl sergantiesiems IS reikalinga kompleksinè sveikatos priežiūra. Reabilitacija, viena iš kompleksinio gydymo komponentų, padeda asmenims pasiekti ir išlaikyti optimalų fizini, psichologinị ir socialinį funkcionavimą sąveikoje su aplinka [2]. I kineziterapijos programą sergantiesiems IS svarbu ịtraukti aerobinès ištvermès lavinimą, raumenų stiprinimo pratimus, pusiausvyros bei pažintinių funkcijų lavinimo užduotis, mažinti nuovargi [3]. Atsižvelgdami ị ligos daugialypiškumą, siekėme išsiaiškinti kompleksinès kineziterapijos programos efektyvumą, ją atliekant skirtingu paros metu, nes tyrimų, kurie nagrinètų kineziterapijos efektyvumą, priklausomai nuo procedūru atlikimo laiko, vis dar trūksta. Nèra aišku, kaip skirtingu paros metu atliekama kineziterapija keičia sergančiųjų IS pusiausvyrą, griuvimo riziką, nuovargị bei pažintines funkcijas.

Darbo tikslas - ịvertinti asmenų, sergančių IS, pusiausvyros, griuvimo rizikos, nuovargio bei pažintinių funkcijų kaitą, taikant kompleksinę kineziterapijos programą, priklausomai nuo procedūrų atlikimo laiko. 


\section{Tyrimo medžiaga ir metodai}

Tyrime dalyvavo asmenys, priklausantys Kauno apskrities sergančiujų išsètine skleroze draugijai. I tyrimą itraukti 40-65 m. asmenys, sergantys IS, gebantys savarankiškai eiti be pagalbos ar poilsio bent $100 \mathrm{~m}$, tiriamujų negalios laipsnis (pagal Kurtzke išplèstinę neigalumo skalę) nuo 2,0 iki 5,5 balų, pažintinių funkcijų vertinimas pagal Monrealio kognityvinị testą - ne mažiau kaip 16 balų. Tyrime dalyvavo 23 asmenys, iš jų 18 moterų ir 5 vyrai. Tyrimą baigè 20 tiriamujų. Tyrimo pradžioje sudarytos dvi tiriamujų grupès: pirmoji - rytinè (2 vyrai ir 8 moterys), antroji - popietine (2 vyrai ir 8 moterys) (1 lentele). Tyrimas buvo atliktas gavus Lietuvos sveikatos mokslų universiteto Bioetikos centro pritarimą (Nr. BEC-JR(M)-176).

Tyrimo metu abiejų grupių tiriamiesiems buvo taikoma ta pati kompleksinè kineziterapijos programa, kurią sudarè tempimo (10 $\mathrm{min}$.), liemens stabilizavimo (20 $\mathrm{min}$.) bei sensomotoriką lavinantys pratimai (15 min.) ir dvigubos užduoties metodas (15 min.). Ši kompleksinè kineziterapijos programa sudaryta pusiausvyros pratimų programos CoDuSe principu [4]. Šios programos taikymui gautas A. Carling ir kitų autorių sutikimas. Kiekvienai tiriamujjų grupei taikyta po 10 kineziterapijos procedūrų, kas antrą dieną. Vienos procedūros trukmè - 1 val.

Tyrimo pradžioje ịvertinta IS sergančių asmenų pusiausvyra (Berg skalè) [5,6], griuvimo rizika (,Stotis ir eiti“ testas $[7,8]$, nuovargis (Daugiamatè nuovargio inventoriaus skale MFI-20) $[9,10]$ bei pažintinės funkcijos (Monrealio kognityvinis testas) [11]. Baigus tyrimą, atliktas kartotinis šių funkcijų ịvertinimas.

1 lentelè. Tiriamujų charakteristika

\begin{tabular}{|c|c|c|c|c|}
\hline $\begin{array}{l}\text { Tiriamoji } \\
\text { grupé }\end{array}$ & \multicolumn{2}{|c|}{ I grupė (proc., n) } & \multicolumn{2}{|c|}{ II grupė (proc., n) } \\
\hline \multirow[t]{2}{*}{ Lytis } & moterys & vyrai & moterys & vyrai \\
\hline & $80(8)$ & $20(2)$ & $80(8)$ & $20(2)$ \\
\hline \multicolumn{5}{|l|}{ Ligos forma: } \\
\hline $\begin{array}{l}\text { Recidyvuojanti } \\
\text { - remituojanti }\end{array}$ & \multicolumn{2}{|c|}{$30(3)$} & \multicolumn{2}{|c|}{$40(4)$} \\
\hline $\begin{array}{l}\text { Antrinè progre- } \\
\text { suojanti }\end{array}$ & \multicolumn{2}{|c|}{$50(5)$} & \multicolumn{2}{|c|}{$50(5)$} \\
\hline \multirow{2}{*}{$\begin{array}{l}\text { Progresuojanti - } \\
\text { remituojanti }\end{array}$} & \multicolumn{2}{|c|}{$20(2)$} & \multicolumn{2}{|c|}{$10(10)$} \\
\hline & \multicolumn{2}{|c|}{$X_{\text {me }}\left(X_{\min }-X_{\text {max }} ; \bar{x}\right)$} & \multicolumn{2}{|c|}{$X_{\text {me }}\left(X_{\text {min }}-X_{\text {max }} ; \bar{x}\right)$} \\
\hline Amžius, metais & \multicolumn{2}{|c|}{$57,5(40-65 ; 55)$} & \multicolumn{2}{|c|}{$57,5(40-65 ; 55)$} \\
\hline $\begin{array}{l}\text { Negalios laips- } \\
\text { nis, balais }\end{array}$ & \multicolumn{2}{|c|}{$3(2-5 ; 3,5)$} & \multicolumn{2}{|c|}{$4(2-5 ; 3,8)$} \\
\hline $\begin{array}{l}\text { Ligos trukmé, } \\
\text { metais }\end{array}$ & \multicolumn{2}{|c|}{$15,5(10-30 ; 18,5)$} & \multicolumn{2}{|c|}{$19(11-33 ; 20,9)$} \\
\hline
\end{tabular}

Statistinè duomenų analizė atlikta naudojant SPSS.21 (angl. Statistical Package for Social Science) bei Excel 2010 programines įrangas. Kiekybiniai tyrimo duomenys pateikiami kaip mediana $\left(X_{m e}\right)$, minimali reikšmè $\left(X_{\min }\right)$, maksimali reikšme $\left(X_{\max }\right)$ ir aritmetinis vidurkis $(\bar{x})-X_{m e}\left(X_{\min }\right.$ $\left.-X_{\max } ; \bar{x}\right)$. Dviems priklausomoms imtims palyginti taikytas Wilcoxon kriterijus. Dviems nepriklausomoms imtims palyginti buvo naudojamas Mann-Whitney-Wilcoxon kriterijus. Skirtumai laikyti statistiškai reikšmingais, kai $\mathrm{p}<0,05$.

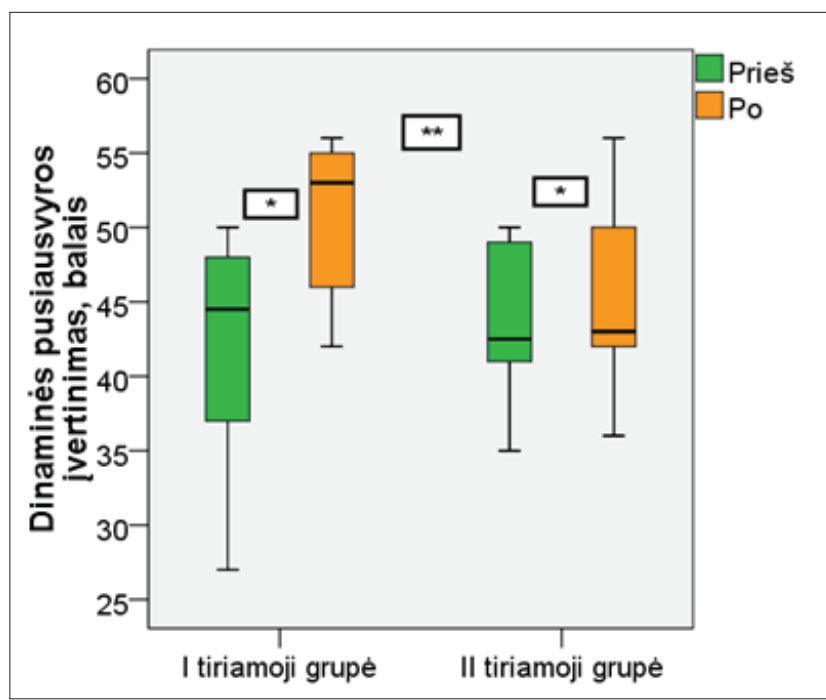

1 pav. Tiriamujų dinaminès pusiausvyros rezultatai prieš intervenciją ir po jos

$* p<0,05$ lyginant rezultatus grupeje prieš ir po kineziterapijos;

** $p<0,05$ lyginant rezultatus tarp grupiu po kineziterapijos.

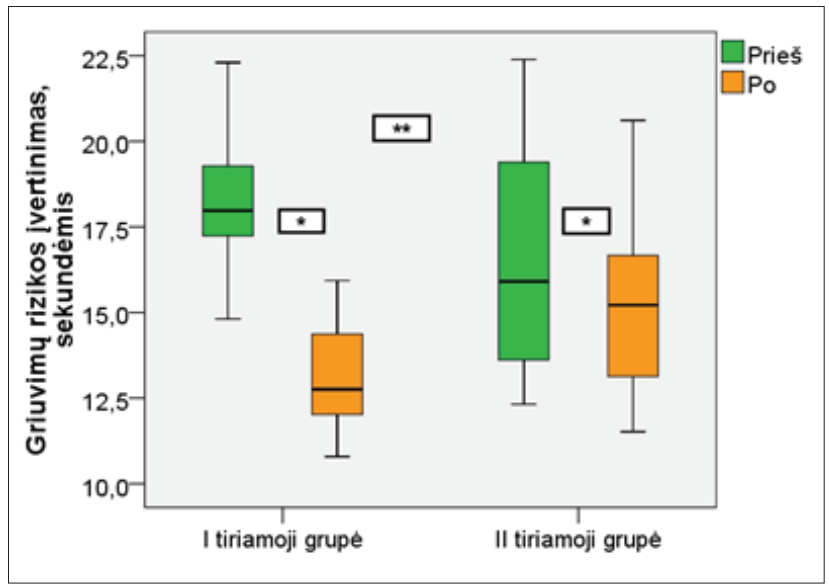

2 pav. Tiriamųjų griuvimų rizikos rezultatai prieš intervenciją ir po jos

$* p<0,05$ lyginant rezultatus grupeje prieš ir po kineziterapijos;

$* * p<0,05$ lyginant rezultatus tarp grupiu po kineziterapijos. 


\section{Tyrimo rezultatai}

Dinaminės pusiausvyros rezultatai po kompleksinès kineziterapijos programos pagerejo abiejose tiriamujų grupèse. Pirminio tyrimo metu pirmos grupès tiriamųų dinaminè pusiausvyra buvo įvertinta $44,5(27-50 ; 42,1)$, o antrojo ištyrimo metu $-53(42-56 ; 51,1)$ balais $(\mathrm{p}<0,05)$. Antros grupès tiriamujų dinaminè pusiausvyra pirminio ištyrimo metu buvo ịvertinta 42,5 (35-50; 43,3), po taikytos intervencijos $-43(36-56 ; 45,2)$ balais $(\mathrm{p}<0,05)$. Lyginant abiejų grupių rezultatus tarpusavyje nustatyta, kad dinaminès pusiausvyros pagerejjimas pirmoje grupèje buvo ženklesnis ( $p$ $<0,05)$ (1 pav.). Dinaminès pusiausvyros rezultatai geresni toje grupejje, kurioje kompleksinè kineziterapijos programa taikyta ryte.

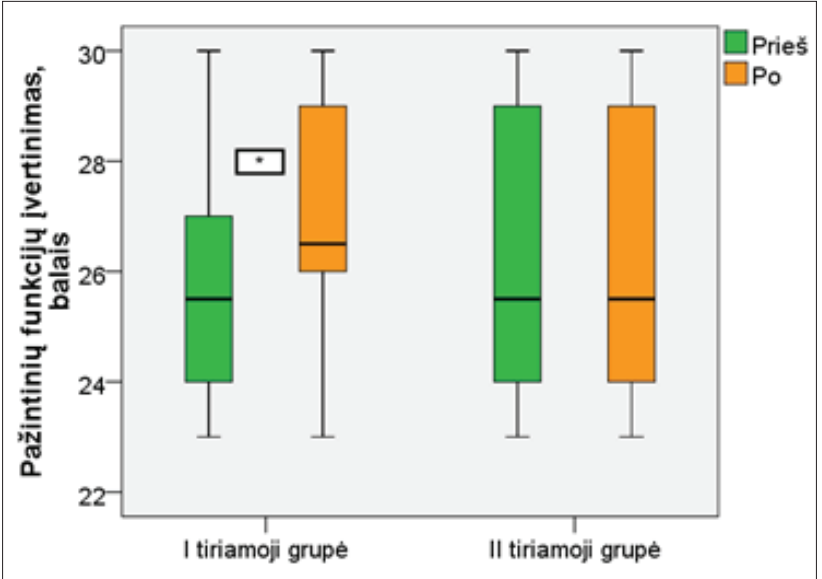

3 pav. Tiriamujų pažintinès funkcijos rezultatai prieš intervenciją ir po jos

$* p<0,05$ - lyginant rezultatus grupeje prieš ir po kineziterapijos.
Griuvimo rizika po taikytos kompleksinès kineziterapijos programos sumažèjo abiejose tiriamosiose grupèse ( $p$ $<0,05)$. Pirmosios grupès tiriamujų griuvimo rizika tyrimo pradžioje buvo i̇vertinta $17,98(14,81-22,3 ; 18,1)$, po kineziterapijos - 12,7 $(10,79-15,93 ; 12,97)$ sekundès $(\mathrm{p}<$ $0,05)$. Antrosios grupes tiriamujų griuvimo rizika tyrimo pradžioje ivvertinta $15,91(12,32-22,39 ; 16,70)$, po tyrimo - 15,22 (11,52-20,61; 15,3) sekundès. Lyginant abiejų grupių rezultatus tarpusavyje, nustatyta, kad po kompleksinès kineziterapijos pirmosios grupès tiriamujų griuvimo rizika sumažejo ženkliau, nei antrosios $(p<0,05)(2$ pav.). Griuvimo rizikos sumažejimas ryškesnis toje grupeje, kurioje kompleksinè kineziterapijos programa taikyta ryte.

Nuovargio vertinimo rezultatai pateikti 2 lentelèje. Bendrasis nuovargis po kompleksinès kineziterapijos programos sumažejo tik pirmojoje grupeje $(\mathrm{p}<0,05)$, antrojoje bendrasis nuovargis tyrimo pradžioje ir pabaigoje nepakito. Po taikytos kompleksinès kineziterapijos programos fizinis nuovargis sumažejo tiek pirmoje, tiek antroje tiriamosiose grupèse $(\mathrm{p}<0,05)$. Fizinio nuovargio rezultatai po intervencijos tarp grupių nesiskyrè. Nustatyta, kad po kompleksinès kineziterapijos programos tiriamųjų aktyvumas padidejjo abiejose grupèse $(p<0,05)$. Aktyvumo rezultatai tarp grupių nesiskyrè. Motyvacija po intervencijos taip pat padidèjo abiejose tiriamosiose grupèse $(\mathrm{p}<0,05)$, motyvacijos skirtumu tarp grupių nenustatyta. Protinio nuovargio pasireiškimas sumažejo tik pirmoje tiriamojoje grupejje $(\mathrm{p}<0,05)(2$ lentelè). Bendrasis ir protinis nuovargis sumažejo tik toje grupeje, kuriai kompleksinė kineziterapijos programa buvo taikyta ryte. Fizinio nuovargio, aktyvumo ir motyvacijos kaita nuo programos taikymo laiko (ryte ar po pietų) nepriklauso.

Pažintinės funkcijos po kompleksinès kineziterapijos programos pagerejo tik pirmojoje grupeje $(\mathrm{p}<0,05)$. Pirmi-

2 lentelè. Tiriamųjų nuovargio rezultatai prieš intervenciją ir po jos

\# 0 proc. - nèra nuovargio, 100 proc. - didžiausias nuovargis; * $p<0,05$ - lyginant rezultatus grupejje prieš ir po kineziterapijos; ** $p<0,05$ - lyginant rezultatus tarp grupiu po kineziterapijos.

\begin{tabular}{|c|c|c|c|c|c|}
\hline \multirow{3}{*}{$\begin{array}{l}\text { MFI - } 20 \text { nuo- } \\
\text { vargio skalė, } \\
\text { proc. }(0-100) \#\end{array}$} & \multicolumn{2}{|c|}{ I tiriamoji grupė } & \multicolumn{2}{|c|}{ II tiriamoji grupè } & \multirow{3}{*}{$\begin{array}{l}\text { Rezultatai } \\
\text { tarp grupių }\end{array}$} \\
\hline & prieš intervenciją & po intervencijos & prieš intervenciją & po intervencijos & \\
\hline & \multicolumn{2}{|c|}{$X_{m e}\left(X_{\min }-X_{m a x} ; \bar{x}\right)$} & \multicolumn{2}{|c|}{$X_{m e}\left(X_{\min }-X_{\max } ; \bar{x}\right)$} & \\
\hline $\begin{array}{l}\text { Bendras nuovar- } \\
\text { gis }\end{array}$ & $\begin{array}{l}68,75(50- \\
100 ; 73,08) \\
\end{array}$ & $\begin{array}{c}53,13 \\
(32,15-93,75 ; 57,59)^{*}\end{array}$ & $56(31,25-100 ; 63,71)$ & $\begin{array}{c}56,25 \\
(25-93,75 ; 56,34) \\
\end{array}$ & $\mathrm{p}=0,912$ \\
\hline Fizinis nuovargis & $\begin{array}{c}65,63(43,75- \\
93,75 ; 65) \\
\end{array}$ & $\begin{array}{c}37,50(25-87,50 \\
46,25)^{*}\end{array}$ & $\begin{array}{c}68,75(31,25-87,50 \\
64,38)\end{array}$ & $\begin{array}{c}53,13(25-81,25 \\
56,88)^{*}\end{array}$ & $\mathrm{p}=0,190$ \\
\hline $\begin{array}{l}\text { Sumažėjęs akty- } \\
\text { vumas }\end{array}$ & $\begin{array}{l}68,75(37,50- \\
93,75 ; 62,51)\end{array}$ & $50(25-87,50 ; 50,63)^{*}$ & $\begin{array}{c}56,25(31,25-100 \\
61,26)\end{array}$ & $\begin{array}{c}31,25(12,50-62,50 \\
31,25)^{*}\end{array}$ & $\mathrm{p}=\mathbf{0 , 0 2 9} * *$ \\
\hline $\begin{array}{l}\text { Sumažėjusi moty- } \\
\text { vacija }\end{array}$ & $\begin{array}{c}56,28(31,25- \\
87,50 ; 58,66)\end{array}$ & $\begin{array}{c}34,38(25-62,50 \\
36,88)^{*}\end{array}$ & $\begin{array}{c}53,13(18,75-81,25 \\
58,13)\end{array}$ & $59,4(25-75 ; 53,13)^{*}$ & $\mathrm{p}=\mathbf{0 , 0 2 3} * *$ \\
\hline $\begin{array}{l}\text { Protinis nuovar- } \\
\text { gis }\end{array}$ & $\begin{array}{c}65,58(31,25-93,73 ; \\
64,37)\end{array}$ & $\begin{array}{c}43,75(25-56,25 \\
40,63)^{*}\end{array}$ & $50(25-87,50 ; 54,38)$ & $\begin{array}{c}56,25(25-81,25 ; \\
58,13) \\
\end{array}$ & $\mathrm{p}=0,063$ \\
\hline
\end{tabular}


nio vertinimo metu, pirmosios grupès tiriamujų pažintinès funkcijos įvertintos $25,5(23-30 ; 25,5)$, po intervencijos $-26,5(23-30 ; 26,8)$ balo. Antrosios grupes tiriamuju pažintinès funkcijos tyrimo metu nepakito: prieš kineziterapiją - 25,5 (23 - 30;26,30), po kineziterapijos - 25,5 (23 $-30 ; 26,40)$ balo. Lyginant pažintinių funkcijų vertinimo rezultatus tarpusavyje, skirtumo tarp grupių nenustatyta (3 pav.). Tiriamujų pažintinès funkcijos pagerejo toje grupeje, kurioje kompleksinè kineziterapijos programa taikyta ryte.

\section{Diskusija}

Išanalizavus tyrimo rezultatus nustatyta, kad kompleksinès kineziterapijos programos taikymas pirmoje dienos pusejje (ryte) yra efektyvesnis, siekiant pagerinti sergančiuju IS dinaminę pusiausvyrą, sumažinti griuvimo riziką, bendrą ir protinị nuovargi bei pagerinti pažintines funkcijas. Tyrimų, kurie vertintų kompleksinès pratimų programos poveikị pusiausvyrai bei griuvimo rizikai priklausomai nuo atliekamos pratimų programos laiko, nèra daug. A. Carling ir kt. [4] bei Y. Nilsagard ir kt. [12] teigia, kad pirmoje dienos pusèje taikoma kompleksiné pratimų programa (liemens stabilizavimo, dvigubos užduoties bei sensomotoriniai pratimai) yra efektyvesnè gerinant pusiausvyrą, eiseną bei mažinant griuvimo riziką. A. Forsberg, ir kt. [13] nustatè, kad kompleksinès pratimų programos taikymas asmenims, sergantiems IS, pagerino statinès ir dinaminès pusiausvyros bei eisenos rodiklius, tačiau autoriai netyrė pratimų programos atlikimo laiko itakos rezultatams. C. Gutierrez ir kt. [14] tyre jègos bei dvigubos motorinès užduoties kombinuotos pratimu programos efektyvumą ir nustate, kad kompleksinè pratimų programa yra efektyvesnè priemoné, siekiant pagerinti statinę, dinaminę pusiausvyrą, jègos vystymo greitị bei sumažinti griuvimo riziką, lyginant su kontroline grupe, kuriai nebuvo taikoma jokia intervencija. Mūsų tyrimo duomenys sutampa su autorių išvadomis, kad kompleksinè kineziterapijos programa yra efektyvi intervencija, siekiant pagerinti sergančiųų IS pusiausvyrą bei sumažinti griuvimo riziką. Siekiant geresnių rezultatų, kompleksinę kineziterapiją tikslinga taikyti pirmoje dienos pusèje.

Mūsų tyrimo rezultatai iš dalies sutampa su I. Bulguroglu ir kt. [15] autorių duomenimis, kad kompleksinè pratimų programa mažina nuovargị, kuris yra susijęs su pažintinèmis bei psichosocialinèmis funkcijomis. E. Grazioli [16] bei W. Mikuláková ir kt. [17] tyrè, kaip tempimo, pasipriešinimo bei aerobinès ištvermès pratimų programa gali veikti nuovargị. Nustatyta, kad būtent ši kompleksinè pratimų programa sumažino fizinį, protinị bei psichosocialinį nuovargi asmenims, sergantiems IS. S. Hameu su bendraautoriais [18] tyrè kitokios kompleksinès pratimų programos (eisenos, pusiausvyros, aerobinès ištvermès bei pasipriešinimo lavi- nimo pratimai) efektyvumą. Pastebèta, kad po kineziterapijos fizinis ir kognityvinis nuovargis reiškèsi mažiau. Vertinant mūsų atlikto tyrimo duomenis, rezultatai iš dalies sutampa su minètų autorių išvadomis, kad kompleksinès pratimų programos taikymas sumažina bendrojo ir protinio nuovargio pasireiškimą asmenims, sergantiems IS, tačiau tyrimų, kurie vertintų nuovargio pasireiškimo rezultatus priklausomai nuo kompleksinès pratimų programos atlikimo laiko, neradome.

C. Qzkul ir kt. [19] tyre kompleksinès pratimų programos efektyvumą IS sergančių asmenų pažintinėms funkcijoms ir nustate, kad po taikytos kompleksinès pratimų programos pagerèjo tiriamųjų ilgalaikès atminties rodikliai, sumažèjo protinis nuovargis. A. Barbarulo su bendraautoriais [20] teigia, kad taikoma kompleksinè pratimų programa, lyginant su iprastine kineziterapija, kuri orientuota ne tik ị pusiausvyros bei eisenos lavinimą, bet ir i pažintines funkcijas, gali padèti pagerinti IS sergančių asmenų dėmesio koncentraciją bei erdvinę atmintị. Nors autoriai nevertinio taikomų programų efektyvumo, priklausomai nuo procedūru atlikimo laiko, mūsų gauti tyrimo rezultatai taip pat patvirtinta autorių išvadas, kad kompleksiné pratimų programa gali pagerinti ne tik pusiausvyros, bet ir pažintinių funkcijų rodiklius.

Apibendrinant, teigiame, kad ryte atliekama kombinuota kineziterapijos programa yra efektyvesnè gerinant sergančiųjų IS dinaminę pusiausvyrą, mažinant griuvimo riziką, bendrojo ir protinio nuovargio pasireiškimą bei gerinant kognityvines funkcijas.

\section{Išvados}

1. Dinaminès pusiausvyros rezultatai geresni toje grupejje, kurioje kompleksine kineziterapijos programa taikyta ryte.

2. Griuvimo rizikos sumažèjimas ryškesnis toje grupejje, kurioje kompleksinè kineziterapijos programa buvo taikyta pirmoje dienos puseje.

3. Bendrasis ir protinis nuovargis sumažejo tik toje grupèje, kuriai kompleksinè kineziterapijos programa buvo taikyta ryte.

4. Tiriamujų pažintinès funkcijos pagerèjo toje grupejje, kurioje kompleksinè kineziterapijos programa buvo taikyta ryte.

\section{Literatūra}

1. Vidal-Jordana A, Montalban X. Multiple sclerosis: epidemiologic, clinical, and therapeutic aspects. Neuroimaging Clin $\mathrm{N}$ Am 2017;27(2):195-204.

https://doi.org/10.1016/j.nic.2016.12.001

2. Amatya B, Khan F, Galea M. Rehabilitation for people with multiple sclerosis: an overview of Cochrane reviews. Cochrane Database Syst Rev 2019;2019(1). 
https://doi.org/10.1002/14651858.CD012732.pub2

3. Motl RW, Smith DC, Elliott J, Weikert M, Dlugonski D, Sosnoff JJ. Combined training improves walking mobility in persons with significant disability from multiple sclerosis: a pilot study. J Neurol Phys Ther 2012;36(1):32-7.

https://doi.org/10.1097/NPT.0b013e3182477c92

4. Carling A, Forsberg A, Gunnarsson M, Nilsagård Y. CoDuSe group exercise programme improves balance and reduces falls in people with multiple sclerosis: a multi-centre, randomized, controlled pilot study. Mult Scler 2017;23(10):1394-404. https://doi.org/10.1177/1352458516677591

5. Berg K, Wood-Dauphinee S, Williams JI, Gayton D. Measuring balance in the elderly: preliminary development of an instrument. Physiother Canada 1989;41(6):304-11.

https://doi.org/10.3138/ptc.41.6.304

6. Cattaneo D, Regola A, Meotti M. Validity of six balance disorders scales in persons with multiple sclerosis. Disabil Rehabil 2006;28(12):789-95.

https://doi.org/10.1080/09638280500404289

7. Ylva Nilsagard, Cecilia Lundholm, Lars-Gunnar Gunnarsson ED. Clinical relevance using timed walk tests and 'timed up and go' testing in persons with multiple sclerosis. Physiother Res Int 2008;11(2):93-103.

https://doi.org/10.1002/pri.358

8. Sebastião E, Sandroff BM, Learmonth YC, Motl RW. Validity of the timed up and go test as a measure of functional mobility in persons with multiple sclerosis. Arch Phys Med Rehabil 2016;97(7):1072-7.

https://doi.org/10.1016/j.apmr.2015.12.031

9. Smets, EMA, Garssen, B, Bonke, B, de Haes J. Pergamon. Fatigue inventory (MFI) psychometric qualities if an instrument to asses fatigue. J Psychosom Res 1995;39(5):315-25.

https://doi.org/10.1016/0022-3999(94)00125-O

10. Lin JS, Brimmer DJ, Maloney EM, Nyarko E, Belue R, Reeves WC. Further validation of the multidimensional fatigue inventory in a US adult population sample. Popul Health Metr 2009; 7:18. https://doi.org/10.1186/1478-7954-7-18

11. Costa AS, Friesen P. Alternate-form reliability of the Montreal cognitive assessment screening test in a clinical setting. Dement Geriatr Cogn Disord 2012;33(6):379-84.

https://doi.org/10.1159/000340006

12. Nilsagård YE, Von Koch LK, Nilsson M, Forsberg AS. Balance exercise program reduced falls in people with multiple sclerosis: a single-group, pretest-posttest trial. Arch Phys Med Rehabil 2014;95(12):2428-34.

https://doi.org/10.1016/j.apmr.2014.06.016

13. Forsberg A, Von Koch L, Nilsagård Y. Effects on balance and walking with the CoDuSe balance exercise program in people with multiple sclerosis: a multicenter randomized controlled trial. Mult Scler Int 2016;2016:7076265.

https://doi.org/10.1155/2016/7076265
14. Gutiérrez-Cruz C, Rojas-Ruiz FJ, de la Cruz-Márquez JC, Gutiérrez-Dávila M. Effect of a combined program of strength and dual cognitive-motor tasks in multiple sclerosis subjects. Int J Environ Res Public Health 2020;17(17):1-12.

https://doi.org/10.3390/ijerph17176397

15. Bulguroglu I, Guclu-Gunduz A, Yazici G, Ozkul C, Irkec C, Nazliel B, et al. The effects of mat pilates and reformer pilates in patients with multiple sclerosis: a randomized controlled study. Neuro Rehabilitation 2017;41(2):413-22.

https://doi.org/10.3233/NRE-162121

16. Grazioli E, Tranchita E, Borriello G, Cerulli C, Minganti C, Parisi A. The effects of concurrent resistance and aerobic exercise training on functional status in patients with multiple sclerosis. Curr Sports Med Rep 2019;18(12):452-7.

https://doi.org/10.1249/JSR.0000000000000661

17. Mikuláková W, Klímová E, Kendrová L, Gajdoš M, Chmelík M. Effect of rehabilitation on fatigue level in patients with multiple sclerosis. Med Sci Monit 2018;24(18):5761-70.

https://doi.org/10.12659/MSM.909183

18. Hameau S, Bensmail D, Roche N, Zory R. Adaptations of fatigue and fatigability after a short intensive, combined rehabilitation program in patients with multiple sclerosis. J Rehabil Med 2018;50(1):59-66.

https://doi.org/10.2340/16501977-2277

19. Ozkul C, Guclu-Gunduz A, Eldemir K, Apaydin Y, Yazici $\mathrm{G}$, Irkec C. Combined exercise training improves cognitive functions in multiple sclerosis patients with cognitive impairment: a single-blinded randomized controlled trial. Mult Scler Relat Disord 2020;45:102419.

https://doi.org/10.1016/j.msard.2020.102419

20. Barbarulo AM, Lus G, Signoriello E, Trojano L, Grossi D, Esposito M, et al. Integrated cognitive and neuromotor rehabilitation in multiple sclerosis: a pragmatic study. Front Behav Neurosci 2018;12(9):1-13.

https://doi.org/10.3389/fnbeh.2018.00196

\section{THE BALANCE, RISK OF FALLS, FATIGUE AND COGNITIVE FUNCTION CHANGES \\ IN INDIVIDUALS WITH MULTIPLE SCLEROSIS USING AN INTEGRATED EXERCISE PROGRAM DEPENDING ON DAY TIME \\ M. Rukaitè, E. Jazepčikienè}

Keywords: multiple sclerosis, a complex physiotherapy exercise program, balance, fall risk, fatigue, cognitive functions.

Summary

Research background. Multiple sclerosis (MS) is presented with multiple symptoms, like balance, fatigue and cognitive functions disorders. Daily fatigue is associated with physical, cognitive, and psychosocial health, not only with the risk of falls, but it also limits patients' daily physical activity and motivation. Considering to the complexity of the disease, we sought to find out whether the combined physiotherapy program affects the indicators of ba- 
lance, risk of falls, fatigue and cognitive functions for people with MS. It is probable that the change of mentioned indicators may also depends on the time of day when the exercises are performed.

The aim - to evaluate the change in balance, risk of falls, fatigue and cognitive functions in individuals with MS using a complex physiotherapy program, depending on the time of the sessions.

Methods. The study involved 20 individuals belonging to the Kaunas District Multiple Sclerosis Society. Participants were divided into two exposure groups. Both groups underwent the same combined physiotherapy program, which included stretching, torso stabilization, and sensorimotor exercises, and a dual-task method. Each group received 10 physiotherapy sessions every other day, 1 hour / day. The first group received physiotherapy in the morning and the second one - in the afternoon. At the beginning of the study, the balance (Berg scale), risk of falls (Timed Up and Go test) fatigue (Multidimensional Fatigue Inventory Scale) and cognitive functions (Montreal Cognitive Assessment) was assessed in individuals with MS. At the end of the study, a re-evaluation was performed.
Results. Evaluating effectiveness of a complex physiotherapy program, depending on procedure time, the first study group results of dynamic balance, fall risk, general and mental fatigue and cognitive functions $(\mathrm{p}<0,05)$ were statistically more significant comparing the results between the groups.

Conclusions. 1. Dynamic balance results were greater in the morning group. 2. Reduce of fall risk also were greater in the study group, which combined program performed in the morning. 3. General and cognitive fatigue reduce only in the morning group. 4. Cognitive functions of subjects improved in the morning group only.

Correspondence to: martyna.rukaite@stud.lsmu.lt

Gauta 2020-11-20 